\title{
Skeptical Hypotheses and Moral Skepticism
}

\author{
Joshua May \\ Published in the Canadian Journal of Philosophy \\ Vol. 43, No. 3 (2013), pp. 341-359. \\ DOI: $10.1080 / 00455091.2013 .857138$ \\ Note: This is the penultimate draft; \\ any citations should be to the final, published version.
}

\begin{abstract}
Moral skeptics maintain that we do not have moral knowledge. Traditionally they haven't argued via skeptical hypotheses like those provided by perceptual skeptics about the external world, such as Descartes' deceiving demon. But some believe this can be done by appealing to hypotheses like moral nihilism. Moreover, some claim that skeptical hypotheses have special force in the moral case. But I argue that skeptics have failed to specify an adequate skeptical scenario, which reveals a general lesson: such arguments are not a promising avenue for moral skeptics to take. They're ultimately weaker when applied to morality compared to perception.
\end{abstract}

Total Word Count: 9,101 (including notes, references, etc.)

Keywords: moral justification, skeptical scenarios, debunking, disagreement, a priori skepticism.

\section{Introduction}

Perceptual skeptics argue that we do not know whether there is an external world of mind-independent objects. They typically invoke the possibility of scenarios in which one fails to have knowledge of an external world, such as Descartes' deceiving demon or the brain-in-a-vat scenario. But one could maintain a similar position about morality, yielding a form of epistemic moral skepticism - the view that no one has any moral knowledge. Such moral skeptics claim, for example, that no one knows whether abortion in the third trimester is immoral. But likewise they argue that no one knows whether it's morally permissible.

There are several ways to deny moral knowledge, and so there are several forms of epistemic moral skepticism. Since, on standard accounts, knowledge of some proposition $p$ requires at least justified, true belief that $p$, one can deny moral knowledge by claiming that one or more of these necessary conditions 
systematically fails to be satisfied with respect to moral beliefs. Strict noncognitivists, for example, deny that moral judgments are truth-apt. So they count as moral skeptics in virtue of denying the existence of moral beliefs; there are only expressions of emotion, or some other kind of non-cognitive state. Other skeptics about moral knowledge, however, admit moral beliefs but deny that there are substantive moral truths. Moral nihilism of various sorts, for example, denies the existence of moral facts - i.e. true moral propositions (e.g. Joyce 2001). ${ }^{1}$ These two forms of skepticism, however, rest primarily on metaphysical claims. A distinctively epistemic version holds that our substantive moral beliefs are simply not justified or lack warrant (e.g. Miller 1985; Joyce 2006, ch. 6). On this taxonomy, all of these views are either a form of (epistemic) moral skepticism or entail it. ${ }^{2}$

Moral skepticism has traditionally been supported by directly arguing for a specific version, such as nihilism or non-cognitivism. But I shall focus on the more epistemic form of the view which denies us moral knowledge because we lack sufficient justification. Moreover, I shall focus on those moral skeptics who, like perceptual skeptics, argue for their position via skeptical scenarios, which appeal to the mere existence of certain hypotheses, without the need to defend their truth, avoiding more tendentious claims about the actual world. A skeptical hypothesis argument for moral skepticism attempts to show that we are not justified in believing any moral propositions (and thus do not know them) because our evidence doesn't rule out certain contrary hypotheses, such as the moral nihilist's claim that there are no moral facts. Thomas Nagel (1971), for example, draws an analogy between perceptual skepticism and the kind of value-skepticism that goes with a sense of life's absurdity. In the perceptual case, Nagel says we ask "why we should believe the evidence of our senses at all" while in the practical domain we ask "not only why we should take aspirin, but why we should take trouble over our own comfort at all" (pp. 723-4). According to Nagel, the "philosophical judgment of absurdity" - a kind of skepticism about life's significance-is supported by "contrasting the pretensions of life with a larger context in which no standards can be discovered" (p. 722). And Nagel concludes that, just as in the perceptual case, we cannot fully escape this skepticism. Similarly, Walter Sinnott-Armstrong (2006) recently argues that moral skepticism in particular lingers in part because there is "no way to rule out moral nihilism" (p. 79).

What are the prospects of vindicating moral skepticism in the way that perceptual skeptics traditionally do by appeal to the mere possibility of skeptical hypotheses? I shall argue that they are rather dim. On any of various characterizations or extensions of such arguments, they fail to specify an adequate

\footnotetext{
${ }^{1}$ Of course moral nihilists will likely want to only deny the existence of certain moral facts, such as positive, atomic, or existentially quantified ones (Sinnott-Armstrong 2006, ch. 3.1). We can set aside such complications here.

${ }^{2}$ Many of the preceding views are simply labeled "moral skepticism." I will sometimes use the term "epistemic moral skepticism" to distinguish the general view that interests us here-i.e. the thesis that we lack moral knowledge. However, for convenience, I will often drop "epistemic" in what follows.
} 
skeptical scenario. Moreover, this general problem with skeptical hypothesis arguments in the moral domain reveals that, not only are they no more powerful for morality than perception, they're weaker. I conclude that skeptical hypothesis arguments are not a promising avenue for moral skeptics to take.

\section{An Initial Skeptical Argument}

Sinnott-Armstrong has done the most to develop a skeptical hypothesis argument for moral skepticism analogous to the argument for perceptual skepticism, with its origin primarily in Descartes. The Cartesian deceiving demon hypothesis is intended to show that it's possible we're being deceived into thinking there is an external world when there is none. Sinnott-Armstrong claims that a similar type of hypothesis applies to the moral case, causing the same problems: "Almost everyone believes that it is morally wrong to torture babies just for fun, but we might be deceived in our beliefs that babies feel pain or that they have moral rights" (2006, p. 78).

Of course, believing in the sentience of babies may not be morally fundamental or in some sense "core." Perhaps it is more of an empirical belief, which combines with decidedly moral beliefs (e.g. about the moral relevance of pain) to render a moral judgment about the torture of babies. In that case, it doesn't pose a challenge for morality proper. Compare the analog in the perceptual case: Suppose almost everyone believes that Kima's jacket is green because Omar told us that Kima's jacket is the same color as this patch of grass, which we see is green. But Omar could have deceived us. While a testimonial belief may combine with a decidedly perceptual belief, we haven't generated a skeptical problem for perception by pointing to the possibility of faulty testimony. Sinnott-Armstrong's reference to beliefs about rights is perhaps more apt for the moral case, since they seem to be relevantly core. So, to generate a skeptical challenge for morality, one must show that core moral beliefs can be illusory.

Perhaps a Cartesian demon could deceive us about such core moral beliefs. Some have doubted this on the assumption that basic moral truths are necessary or known a priori, and we'll consider this issue in due course (in §5). But SinnottArmstrong worries that demon hypotheses are simply too outlandish to warrant anyone's consideration. So he formulates the argument in terms of "the skeptical hypothesis of moral nihilism" (p. 74). In fact, he thinks this makes the skeptical hypothesis argument against moral knowledge even more powerful than the analog argument against perceptual knowledge. Moral nihilism after all has more proponents and it leaves less unexplained, unlike the brain-in-a-vat or deceiving demon scenarios (2006, p. 124, n. 6; cf. 2008b, pp. 227-8). Thus, he says that such "skeptical arguments have special force within morality" (p. 74), which we can label the Special Force Claim. This is an important claim to scrutinize since skepticism about morality is often motivated by the thought that it suffers from 
special epistemological problems not shared in other domains (or at least not to the same extent). ${ }^{3}$

Following the standard "closure argument" for perceptual skepticism that has become so popular, Sinnott-Armstrong's initial argument involving moral nihilism is as follows (pp. 79-80, my emphasis):

Initial Skeptical Hypothesis Argument for Moral Skepticism

1. I am not justified in believing that moral nihilism is false.

2. I am justified in believing that $(p)$ 'It is morally wrong to torture babies just for fun' entails $(q)$ 'moral nihilism is false.'

3. If I am justified in believing that $p$, and I am justified in believing that $p$ entails $q$, then I am justified in believing that $q$.

4. Therefore, I am not justified in believing that $(p)$ it is morally wrong to torture babies just for fun.

There are several things to note about this argument. First, as SinnottArmstrong points out, it is meant to generalize to all moral beliefs; there is nothing special about this particular moral belief about torture (p. 80). Second, the argument is formulated in terms of justification, but it is supposed to apply to knowledge as well insofar as knowledge requires something like justification (p. 80, n. 26). Third, the final premise is an instance of a principle of closure. Such principles are notoriously difficult to formulate in ways that make them immune to counter-examples. But the reader can substitute whichever version seems most plausible. Fourth, according to Sinnott-Armstrong, this is all apparently based on a "common standard for justified belief" (p. 78) according to which "I am not justified in believing something if there is any contrary hypothesis that I cannot rule out" (p. 77). A similar idea can be found in Nagel: "all our decisions and certainties [which assume life is significant] are possible only because there is a great deal we do not bother to rule out" (1971, p.723). Perhaps one must be aware of the contrary hypotheses if they are to threaten justification when unable to be ruled out, but the idea is clear and plausible enough on its face. ${ }^{4}$

Following Sinnott-Armstrong, I will bypass discussion of attempts to rebut such skeptical hypothesis arguments by denying either the second or third premise. In the above argument, the crucial premise is the first one, namely, that I lack justification for believing that I'm not in the skeptical scenario. This claim relies on an argument involving the details of the skeptical scenario and specifically how one's evidence fails to show that the skeptical scenario is less likely than the ordinary scenario involving an external world. So the subsequent discussion will focus on support for the first premise.

\footnotetext{
${ }^{3}$ For a recent discussion of - and attack on — this general idea that there are special epistemological problems for moral beliefs, but as compared to mathematical beliefs, see Justin Clarke-Doane (forthcoming).

${ }^{4}$ Sinnott-Armstrong's particular take on his argument is complicated by his contrastive theory of justification (see chs. 5-6). Skeptical hypothesis arguments for moral skepticism can be framed without taking a stance on the further issue of contrastivism, so we can set it aside.
} 
At any rate, the Initial Argument is intended to be analogous to the familiar argument for perceptual skepticism that is underwritten by the famous brain-in-avat (BIV) scenario: ${ }^{5}$

Closure Argument for Perceptual Skepticism

1. I'm not justified in believing that: I'm not a BIV.

2. I am justified in believing that: I have hands entails I'm not a BIV.

3. If I'm justified in believing that $p$ and that $p$ entails $q$, then I'm justified in believing that $q$.

4. So: I'm not justified in believing that I have hands.

Of course, like the Initial Argument for moral skepticism, this argument is supposed to generalize to all propositions about mind-independent physical objects. If I'm not justified in believing that I have hands because I'm not justified in believing I'm not a BIV, then I am likewise not justified in believing there are any other mind-independent physical objects.

Sinnott-Armstrong's Initial Argument is analogous in some important respects to proper skeptical hypothesis arguments. First, both attempt to systematically undermine the relevant beliefs of any ordinary person. The challenge is not to a small, idiosyncratic set of beliefs or people. Second, skeptical hypothesis arguments challenge the alleged justification (or warrant) for one's beliefs and they do so by merely appealing to the possibility of a skeptical scenario (cf. Brueckner 1994). The skeptic's first premise contends that one is not justified in believing the skeptical hypothesis is false, not because we have good reason to believe it's true, but rather because one cannot rule it out. Moreover, this poses a problem for one's knowledge by undermining one's justification, not by directly arguing that other conditions on knowledge aren't met, such as the truth of what's believed. Such approaches amount to distinct skeptical challenges that are not our focus here. These various features of skeptical hypothesis arguments are not superficial or incidental either, as they are the source of their powerful scope and special significance. Thus, they provide constraints on what counts as an argument of this type.

Notice, however, that there is a crucial disanalogy between SinnottArmstrong's Initial Argument and the Closure Argument for perceptual skepticism. While the brain-in-a-vat and evil demon scenarios are genuine skeptical scenarios, moral nihilism alone isn't. ${ }^{6}$ Moral nihilism is just the metaphysical view that there

\footnotetext{
${ }^{5}$ I assume familiarity with the details of the BIV scenario. For a helpful discussion of the "closure" structure of the skeptical hypothesis argument, see Anthony Brueckner (1994).

${ }^{6}$ I owe special thanks to Aaron Zimmerman for first making this general worry salient to me. Zimmerman (2010) addresses Sinnott-Armstrong primarily on fronts other than the skeptical hypothesis argument, such as the regress argument and Harman-style arguments against abductive moral knowledge (see chapters 4 and 6, respectively). However, he does mention (in ch. 5) the idea that distinctively epistemic arguments for moral skepticism based on skeptical scenarios must describe said scenarios in sufficient detail in order to have any force (see esp. p. 122). James Beebe (2010, sect. 1) also makes this general point about skeptical hypotheses.
} 
are no moral facts. The analog of moral nihilism in the debate about perceptual skepticism is something like idealism, which let's just stipulate is the view that there are no mind-independent objects. Of course, idealists might not put it this way. They would likely maintain that we do have hands but that they are simply ideas or mind-dependent objects. After all, even Berkeley thought he was defending common sense (cf. Sinnott-Armstrong 2008b, p. 224). In any event, we simply need a label for the relevant view, and "idealism" as normally understood can be used for our purposes. We need only assume that "hands" as it occurs in the skeptical arguments is meant to refer to essentially mind-independent objects. In other words, idealism (in this sense) is one way to render false our ordinary beliefs about hands and other parts of the external world. Thus, like nihilism, idealism is in some sense a skeptical hypothesis, but to become what we might separately call a skeptical scenario we need further details showing that one cannot rule it out, and in a way that renders one's beliefs unjustified.

Comparing nihilism to idealism, the perceptual analog to Sinnott-Armstrong's argument for moral skepticism is really this:

\section{Odd Argument for Perceptual Skepticism}

1. I'm not justified in believing that idealism is false.

2. I'm justified in believing that: I have hands entails idealism is false.

3. If I'm justified in believing that $p$ and that $p$ entails $q$, then I'm justified in believing that $q$.

4. So: I'm not justified in believing that: I have hands.

This form of argument entails we're not justified in believing perceptual realismthat there is an external world of mind-independent objects-which is a metaphysical theory, not a skeptical scenario. Yet this is already guaranteed by the first premise. The rest of the argument is simply drawing out particular consequences of lacking justification for rejecting idealism. This is not a skeptical hypothesis argument. The traditional brain-in-a-vat and deceiving demon cases are attempts to spell out the details of a skeptical scenario in which one's relevant beliefs are false while the support for them remains fixed. In addition to moral nihilism, Sinnott-Armstrong also says that other "extreme hypotheses" can work just as well. He mentions ethical egoism and moral relativism (p. 79, n. 22), but these suffer from the same problems. While they may be in some sense skeptical hypotheses, they alone are not skeptical scenarios, since they don't specify how our evidence fails to rule out these hypotheses. (Moreover, egoism and relativism can serve the same role as nihilism only if moral judgments can never be true if they're ultimately self-interested or subjective; this requires some argument.) ${ }^{7}$

The details of such a skeptical scenario must involve what we might call an "evidence-truth gap" between the relevant epistemology and metaphysics (cf. Audi 1997, p. 67; Bergmann ms). The famed brain-in-a-vat scenario, for example, is

\footnotetext{
${ }^{7}$ The use of "evidence" and similar terms throughout isn't meant to presuppose evidentialism or anything like it. Perhaps some moral beliefs are basic and thus don't require anything like positive evidence or justification; we simply have a default "entitlement" to them (cf. Burge 2003). If so, read "evidence" as including broader notions like warrant, which includes such entitlement.
} 
meant to show that one's evidence about the external world would be the same even if one were a handless brain in a vat. It is not meant to show that idealism is true or that we're not justified in believing it's false. The point of the scenario is merely to substantiate the first premise of the main skeptical hypothesis argument: that I'm not justified in believing that I'm not in the skeptical scenario. More precisely, a skeptical scenario must establish, among other things, the following:

\section{Equal Evidence Claim}

The evidence for one's ordinary belief that $p$ (e.g. I have hands) does not provide better evidence for $p$ than for skeptical hypothesis $q$ (e.g. I'm a handless BIV). ${ }^{8}$

The further epistemic assumption is that: if this Equal Evidence Claim applies to a particular belief, then one is not justified in holding it (cf. the Underdetermination Principle in Bruckner 1994). This is closely related to the idea, as SinnottArmstrong puts it himself, that: "When both of two hypotheses would predict an observation, that observation cannot be used as evidence for one as opposed to the other" (p. 191). The idea in the perceptual case is that I'm not justified in believing there is anything out there beyond my experiences because my evidence (perceptual experience) does not "rule out" the skeptical hypothesis that I am a brain in a vat. After all, everyday perceptual illusions show that perceptual experiences are compatible with both: (a) things are the way they seem (e.g. I have hands), and (b) things aren't the way they seem (e.g. I'm a handless BIV). Consider the famous hollow-mask illusion in which a concave mask appears to us as convex, just as a normal face is. Such illusions seem to show that perceptual experiences are in some sense compatible with the world being the way they represent it and with the world being some other way. ${ }^{9}$

In the case of perception, the skeptic and her opponent are assumed to have a fairly similar view about the epistemology and metaphysics of external objects. And this common ground allegedly leads to a perceptual version of the Equal Evidence Claim. The epistemology is supposed to be (roughly) one according to which one's perceptual beliefs are based on perceptual experiences, which provide a mental representation of the objects. And the metaphysics is supposed to be (roughly) one according to which objects in an external world are mind- or

\footnotetext{
${ }^{8}$ Cf. Feldman (2003, p. 142). This is also similar to Beebe's (2010) account of one criterion for skeptical hypotheses, though he focuses on "subjective indistinguishability" (p. 466). I worry about framing the issue in terms of one's experiences (cf. §5), but it may be a preferable formulation for those who tendentiously claim that one's evidence for a belief differs depending on whether the belief is true.

${ }^{9}$ The traditional BIV scenario involves hallucination rather than illusion. But some theorists believe hallucinations aren't perceptual experiences. If such theorists are right, then a scenario involving hallucination might not involve the same evidence as when we are normally perceiving objects (whereas veridical perception and illusion presumably would). If so, then the moral skeptic's scenario should be amended just as the BIV scenario should so that they involve illusion rather than hallucination. For simplicity, I'll simply suppose such a modification has been made and speak of the BIV experiencing an illusion.
} 
observer-independent. In other words, there must be a gap between one's evidence and the purported facts in order for the skeptical challenge to get off the ground at all. That is why certain views about perception diffuse the challenge, although at the expense of denying what seems to be the intuitive metaphysics and epistemology of perception. Phenomenalists, in claiming that physical objects are nothing but constructions out of phenomenological experiences, close the gap between the epistemology and the metaphysics by modifying the traditional account of the metaphysics to fit directly with the assumed account of the epistemology. Direct realists about perception, in claiming that we are directly acquainted with physical objects of the external world, make the opposite move: they close the gap by modifying the assumed account of the epistemology to fit directly with the traditional account of the metaphysics.

Without further support, the Initial Argument as is doesn't fully grapple with the Equal Evidence Claim. It isn't obvious that the evidence for our moral beliefs is compatible with both moral nihilism and its denial in a way that undermines one's justification. So this requires defense. While the Initial Argument is perhaps not the only way to formulate a skeptical hypothesis argument, the other ways to extend the proposal likewise suffer from one or more substantial problems. I address these in turn.

\section{Moral Nihilism and Disagreement}

There is another way to interpret the moral skeptic's proposal, and one that makes a clear claim about what our evidence is. At one point, Sinnott-Armstrong does write:

[Moral nihilism] is constructed so as to leave no way to rule it out. Since moral nihilists question all of our beliefs that anything is morally wrong, and so on, they leave us with no moral starting points on which to base arguments against them without begging the question at issue. (p. 79)

But this again is disanalogous to skeptical hypothesis arguments for perceptual skepticism. Recall that the analog of moral nihilism is something more like idealism. Just as the opponent of the anti-skeptic about perception is not specifically the idealist, the opponent of the anti-skeptic about moral knowledge is not specifically the moral nihilist.

Moreover, even if we replace the idealist with the skeptic, anti-skeptics about any domain needn't convince the skeptic. As several commentators have pointed out in the perceptual case, the primary goal is to undermine the skeptic's arguments - to provide good reasons to reject them - not to convince the skeptic. We mustn't conflate dialectical and epistemic issues (cf. Feldman 2003, p. 121; Rescorla 2009). To take a simple example, suppose Fred believes the earth is flat, and we try to convince him otherwise. We might have the dialectical goal of convincing him that the planet is roughly spherical. And this might be underwritten by a concern to improve Fred - to get him to correct his belief. Or perhaps we might just want to alleviate the anger his ignorance gives rise to in us. But 
presumably such dialectical goals are not primary in epistemology. Rather than attempting to convince particular people of certain theses, we examine arguments to see whether they are any good, which is a decidedly epistemic goal. Whether the topic is perception or morality, we look to evaluate the arguments; an emphasis on a dialogue or dialectic is misleading.

Perhaps, though, one could argue that focusing on a dialogue reveals that peer disagreement is precisely the skeptical hypothesis that undermines our moral beliefs (cf. Wedgwood 2010). Our skeptic might then rely on the following empirical claim, albeit a controversial one: equally informed and intelligent people (so-called "epistemic peers") disagree about whether a hypothesis like moral nihilism is true. One might then add the epistemic thesis that in such circumstances one cannot reasonably continue to hold a belief in the relevant hypothesis or its denial. This resembles what is often called the "equal weight view" (Elga 2007). While one could raise doubts about this view (see e.g. Wedgewood 2010), let us grant it for the sake of argument. This line of thought would establish the first premise of something like the Initial Argument. It remains focused on moral nihilism but fleshes out a skeptical hypothesis in which one's evidence fails to rule it out, apparently satisfying the Equal Evidence Claim. Thus, from a claim about disagreement and a thesis about its relevance, we might seem to arrive at a skeptical hypothesis argument. And it's one that can potentially establish the Special Force Claim insofar as disagreement seems especially deep or extensive in ethics.

There are several problems with this approach. One is that shifting the focus to something like peer disagreement will actually militate against the Special Force Claim. After all, there are clearly substantive disagreements among ordinary people in areas besides morality as well as among specialists about nearly every theory in philosophy, including idealism, which is our perceptual analog of nihilism (McNaughton 2008, p. 210; Wedgwood 2010, §4). In fact, in virtually any domain, there are people who may well be equally informed and intelligent but deny the existence of entities in that domain - from beliefs and desires to tables and chairs to even numbers (cf. Clarke-Doane forthcoming, §1).

Another problem with focusing on such peer disagreement is that it simply fails to match the scope of skeptical hypothesis arguments. Such arguments are meant to pose a problem for everyone, not just ethical theorists. The relevant perceptual skeptics do not argue that philosophers lack sufficiently compelling or nonquestion-begging arguments against theories like idealism or perceptual skepticism. Instead, they maintain that ordinary people's evidence (perceptual experience, not theoretical argument) doesn't provide more evidence for their ordinary perceptual beliefs (e.g. that they have hands) than for the skeptical hypothesis that they are handless brains in vats. A proper skeptical hypothesis argument for moral skepticism should appeal instead to the nature of the evidence for one's ordinary moral beliefs.

Perhaps the argument could be reformulated to broaden its scope, including disagreements among non-philosophers. A skeptic might argue that, unlike most other philosophical issues, many ordinary people deny that there are moral facts (cf. Sinnott-Armstrong 2008b, p. 224). But this is dubious for several reasons. 
While some non-philosophers may come to reject certain norms, this often concerns rules that don't exhaust the moral domain, such as those handed down from religious authorities. Of course, in contrast to topics such as physics or history, there may be more frequent or substantive disagreement among nonphilosophers about particular moral issues, such as abortion or homosexuality. However, many have recognized that much of this seems to rest on disagreement about non-moral facts (Zimmerman 2010, pp. 28-9), which fails to address core moral beliefs. Moreover, to use ordinary peer disagreement as a skeptical hypothesis, we need cases of non-philosophers who are at least roughly epistemic peers and who disagree about all core moral facts, otherwise the argument cannot generalize. Moreover, presumably ordinary people must be aware of these peers for their existence to threaten justification. Even if there are some people for whom all of these conditions are met with respect to some of their core moral beliefs (cf. Wedgwood 2010, §1), there are likely few such people and few such beliefs. Thus, the argument from disagreement fails to systematically target the justification of ordinary moral beliefs.

Another problem-and this is the most important one-is that skeptical arguments involving disagreement must defend controversial claims about actual scenarios (as in e.g. Miller 1985). If framed in terms of the mere possibility of such disagreement, it lacks skeptical purchase, since, as already noted, one's justification seems undermined by disagreement only if one is aware of its actual existence. Yet, as we've seen, part of the allure of skeptical hypothesis arguments is their ability to pose an epistemological challenge that relies on merely hypothetical scenarios, such as the brain-in-a-vat or demon scenarios, without assuming or defending their truth. Targeting one's beliefs by appeal to something like actual peer disagreement involves a different, and importantly more contentious, style of argument. Wedgwood, for example, rightly notes that the problem of moral disagreement that he discusses yields "a different argument for scepticism from the argument that is based on the mere possibility of an evil demon" (2010, p. 221).

We have identified a number of features of skeptical hypothesis arguments that are missing once we focus on disagreement. Our goal is to determine whether moral skeptics can defend their view with a particular form of argument and in a way that establishes the Special Force Claim. It doesn't appear that this can be done by focusing on disagreement, whether among theorists or non-specialists.

\section{Moral Nihilism and Debunking}

Perhaps we should not focus on moral nihilism alone, since it is often accompanied by a kind of "debunking explanation" of how we form our moral beliefs. Nihilists, after all, do often provide a story about how our moral beliefs are acquired in a way that renders them unjustified - e.g. by relying on psychological traits we've acquired through the presumably non-truth-tracking process of evolution (cf. Joyce 2006). At one point, Sinnott-Armstrong does write: "Such moral beliefs appear obvious to almost everyone who is not a moral nihilist, but that appearance is just what would be predicted by the moral nihilist's hypothesis that all moral beliefs are 
evolutionary or cultural illusions (just as Descartes' hypothesis predicts our experiences)" (p. 191, my emphasis). This leaves many questions unanswered. What exactly is the moral nihilist's hypothesis that our moral beliefs are evolutionary or cultural illusions? What is the evidence for our moral beliefs, and how does it fail to rule out these hypotheses?

The answers are lacking because debunking arguments with a distinctly epistemic conclusion tend to yield an account of how our moral beliefs are unjustified without specifying a scenario that fits with the Equal Evidence Claim. This should be expected, since such arguments aren't meant to establish moral skepticism via anything like an evil demon or brain-in-a-vat scenario. In fact, such genealogical debunking explanations and arguments for moral nihilism are not so intimately connected. Richard Joyce (2001), for example, has provided an argument for nihilism that is independent of his later debunking explanation. In short, he argues that moral beliefs presuppose the existence of special "external" reasons, but there aren't any. His later argument, however, is for the conclusion that our moral beliefs aren't justified, not that they are false-a point Joyce himself emphasizes. He argues only that "our moral beliefs are products of a process that is entirely independent of their truth, which forces the recognition that we have no grounds one way or the other for maintaining these beliefs" $\left(2006\right.$, p. 211) ${ }^{10}$ But this is not a skeptical hypothesis argument, because it doesn't satisfy the Equal Evidence Claim. It doesn't describe a scenario illustrating that the reasons for our moral beliefs fail to provide better support for their truth rather than the hypothetical scenario that they are illusory (i.e. seem true but aren't). As with the appeal to disagreement, a debunking explanation rests on the truth of the relevant hypothesis, not its mere possibility. ${ }^{11}$

Perhaps a skeptic could simply appeal to the possibility of a genealogical debunking explanation of moral belief. But merely describing a possible debunking hypothesis for some moral beliefs doesn't necessarily establish the Equal Evidence Claim for morality. While the hypothesis is only assumed to be possible, not necessarily plausible, it must illustrate something about our actual evidencenamely, that it underdetermines the skeptical versus the non-skeptical hypotheses. Without this further explanation, we're left with only the claim that our evidence could be faulty in the relevant way. Consider, for comparison, the belief many of us have that $2+2=4$, which we can hopefully claim without controversy isn't justified by visual experience. But imagine a skeptic says: "It's logically possible that your belief that $2+2=4$ is based on visual perception, which is compatible with it being illusory, as illustrated by this BIV scenario...." This doesn't pose a skeptical hypothesis challenge at all since it doesn't connect with $m y$ evidence. It matters little to me that vision can be illusory when my mathematical belief is based on

\footnotetext{
${ }^{10}$ Joyce still holds fast to his old view; he simply understands the arguments as separable (see 2006, n. 17, p. 244).

${ }^{11}$ The same issue applies to non-evolutionary debunking arguments, such as those appealing to empirical evidence of irrelevant factors influencing our beliefs and other attitudes (cf. SinnottArmstrong 2006, §9.4.3; Doris 2009).
} 
different evidence. The upshot is that, again, those developing a skeptical hypothesis argument (rather than some other argument for skepticism) must specify the evidence we have for our beliefs of the relevant sort, and then describe a scenario in which this evidence is compatible with the falsity of those beliefs. So we need to know roughly what our evidence is in order to construct a skeptical scenario that challenges it.

There admittedly isn't a very specific story about the scientist in the BIV scenario, so we might think we can do the same in the moral case. For example, perceptual skeptics don't (and needn't) say what chemicals are used to keep the brain alive, what color hair the scientist has, and so on. These details of course aren't relevant for the argument. Skeptics do, however, need to characterize what our evidence is and what it supports - i.e. they must establish the relevant version of the Equal Evidence Claim. Suppose, for example, that a perceptual skeptic says only this: "It could be that your perceptual beliefs are illusory." That may sound like a challenge worth taking seriously, but only because we have a rather clear idea about how it could be fleshed out. Without that, it doesn't pose a skeptical challenge at all. Perceptual skeptics capitalize on the fact that perceptual beliefs seem justified by perceptual experiences, which can seem to be entirely compatible with things being as they appear or not. This derives from a fact about what seems clearly to be the justification or warrant for our perceptual beliefs. So a skeptical hypothesis argument must provide a scenario that appeals to what is plausibly our actual evidence for our moral beliefs and motivates the idea that this evidence underdetermines appearance versus reality. Given that what justifies our moral beliefs seems rather unlike what justifies our perceptual beliefs (more on this in the next section), moral skeptics need to motivate the idea that our moral beliefs are subject to a skeptical hypothesis argument.

A debunking explanation could satisfy the Equal Evidence Claim provided the evidence for our moral beliefs does systematically underdetermine appearance versus reality. Suppose, for example, that our core moral beliefs are based on intuitions relevantly similar to experiences. In perhaps much the same way we acquire justified perceptual beliefs, certain moral propositions may just seem intuitively obvious to us, and our belief is based on this "seeming" or intuition (cf. Wedgwood 2010). If these intuitions are like perceptual experiences in that they are mental representations subject to systematic misrepresentation, then one may be able to generate a skeptical hypothesis with them. A moral skeptic might argue, for example, that we have the moral intuitions we do precisely because they were fitness-enhancing for our ancestors (in the environment of evolutionary adaptedness); yet natural selection doesn't track the moral truth, so they are unwarranted.

However, notice that, when used in a skeptical hypothesis argument, no skeptical work is done by the debunking explanation. The real work is done by the claim about our moral evidence and how it is similar enough to perceptual experiences that it satisfies the relevant Equal Evidence Claim. So again the success of the argument depends on fleshing out the evidence we have for our moral beliefs. The genealogical story provides an explanation for how we came to acquire the beliefs, but it alone does not show that the warrant for our core moral 
beliefs depends on these intuitions. Focusing on such genealogical accounts is a red herring, as they provide "defeaters" for our moral beliefs that may or may not support the Equal Evidence Claim. So, rather than pointing to explanations of the origin of our moral beliefs, our skeptic should construct a more traditional kind of scenario akin to an evil demon. This is an improvement, but we'll turn now to the problems afflicting this more traditional formulation of the skeptical argument.

\section{A More Traditional Approach}

So perhaps we should simply drop moral nihilism as a skeptical hypothesis and rely on more traditional scenarios, such as an evil demon who deceives us about our moral beliefs. This of course immediately undermines the Special Force Claimthat moral beliefs are especially susceptible to skeptical hypothesis arguments. Unlike moral nihilism, intelligent people do not argue for the existence of such a demon or anything like it. So we are immediately down to skeptical hypothesis arguments for moral skepticism being no better than their perceptual analogs. This is not necessarily devastating, though, since one could concede it without losing skepticism about justified moral belief (cf. Sinnott-Armstrong 2008b, §2.1). Nevertheless, if our moral beliefs are merely subject to the kind of scenarios skeptics raise against our perceptual beliefs, then we haven't discovered a special epistemological problem for morality.

More importantly, even if our skeptic constructs a scenario that is not so outlandish as an evil demon, any such approach will still undermine the Special Force Claim, and even more drastically. As we'll see, constructing such skeptical scenarios is more difficult in the moral case, not merely just as difficult (or easy) as with perception. We can begin to see this by noting once again that the skeptical scenario has not yet been fully fleshed out. It must establish a version of the Equal Evidence Claim for the moral case. We need enough of an account of moral truths and our reasons for believing them to construct a scenario supporting the Claim. That is, our evidence for our moral beliefs must be plausibly compatible with their being illusory. In the previous section, we encountered the idea that moral beliefs are based on intuitions that are relevantly like perceptual experiences. But now we must consider whether this is a plausible account of what supports core moral beliefs and, even if so, whether this is sufficient to generate a skeptical hypothesis argument.

An initial problem is that a skeptical scenario presumably can't even get off the ground if our justification for our core moral beliefs is a priori or if the contents of those beliefs are necessarily true. While somewhat controversial, the existence of a priori justification and necessary moral truths is more plausible, or at least more often defended, in the case of morality than perception. Suppose one of our core moral beliefs is in something like the Principle of Utility: One should maximize aggregate happiness. Or consider a Kantian moral principle: always treat humanity as an end, never merely as a means. Such principles have often been deemed necessary or known a priori. While these are theoretical principles, something like the Golden Rule is a possible candidate as well for something that might serve as a 
core moral belief of ordinary folks. In any event, as Sarah McGrath (2010) has recently put it, the consensus among philosophers seems to be that the warrant for our moral beliefs does not seem to paradigmatically involve experimentation or induction via observation; thus, "moral knowledge seems to resemble mathematical knowledge more than it resembles the kind of knowledge that is delivered by the empirical sciences" (pp. 108-9). After all, one's core moral beliefs tend to seem just obvious or self-evidently true, grounded in one's grasp of moral concepts. While there are some dissenters, this is something moral epistemologists seek to either capture or explain away.

Take first the idea that basic moral truths - whatever they may be-are necessary. There is a rather intuitive way to motivate this via the phenomenon of "imaginative resistance" recently popularized by Tamar Gendler (2000). When constructing a story, it is rather difficult (to say the least) for an author to get readers to imagine that women are inherently inferior to men, that causing pain is usually the right thing to do, that one's own interests are always more important than others', and so on. The problem seems importantly similar to trying to get readers to imagine that five is an even number. Yet we have no problem imagining that Neo is in the Matrix, in which his perceptual experiences are radically illusory. Why is this? Perhaps it is because basic moral truths are (metaphysically) necessary, which could explain the difficulties we have in imagining moral facts being otherwise. Yet if basic moral beliefs are necessarily true (if true at all), it isn't even possible for there to be a scenario in which the beliefs are illusory - in which they seem true but aren't. This doesn't entail that no interesting epistemological challenge can be made against beliefs in necessary truths (cf. Clarke-Doane forthcoming); it just won't take the form of a skeptical hypothesis argument. ${ }^{12}$

Of course, it is difficult to determine whether the basic moral propositions we believe are good candidates for necessary truths, or even whether imaginative resistance can shed any light on this. What is at least clear is that perceptual beliefs and the evidence on which they're based are in an important way different from moral beliefs and moral evidence. This makes it all the more difficult to generate a skeptical argument for moral skepticism.

Some of these differences between morality and perception may derive from the plausibly a priori nature of some moral justification, regardless of any alleged metaphysical necessity. In particular, the nature of moral evidence may not establish the Equal Evidence Claim, or at least not in a way that undermines one's justification. If our core moral beliefs are in some sense self-evident, so that one's understanding of the proposition believed is sufficient for justification, then this

\footnotetext{
${ }^{12}$ We might be able to resist the skeptical argument by maintaining an even weaker modal claim: regardless of whether moral truths are necessary, they remain true in "nearby" possible worlds. Given the strong supervenience of the moral on the non-moral, core moral beliefs seem "safe" in that they're only false in possible worlds that are radically different from the actual world (cf. Wedgwood 2010, §2). This, however, relies on the controversial assumption that a safe belief is insulated from skeptical hypothesis arguments. After all, the brain-in-a-vat or evil demon world is radically different from the actual world. When it comes to skeptical hypothesis arguments, the idea is supposed to be that any mere metaphysical possibility, however remote, undermines justification. So I will not press this reply here.
} 
may well provide more support for it than any contrary hypotheses (cf. ShaferLandau 2003, p. 250). Such moral beliefs would resemble the belief that five is prime in that one's understanding of arithmetic concepts seems to justify the belief regardless of alternative hypotheses. In that case, like perceptual "dogmatists" (e.g. Pryor 2000), the moral dogmatist would emphatically deny that the warrant we have for our moral beliefs supports them no better than skeptical hypotheses, whatever they may be. These issues aren't uncontroversial, but the point again is that the reasons for our core moral beliefs seem, on the face of it, to be rather unlike those for our perceptual beliefs, and that spells trouble for the moral skeptic who wants to provide a skeptical hypothesis argument. Even if dogmatism about perception is a revisionary account with the burden of proof, that status doesn't seem to transfer over to the moral case.

These sorts of problems are part of the reason many philosophers believe skeptical scenarios can't be leveled against a priori knowledge. James Beebe $(2010 ; 2011)$, however, has recently provided what he takes to be a skeptical hypothesis argument for any putatively a priori knowledge of a necessary truth. His central case is that of a "bumbling evil demon" who tries to exploit the intellectual seemings that allegedly support our beliefs in "putatively a priori necessities," such as $2+3=5$ or basic truths of logic. The demon tries to give us the feeling of veridicality (so to speak) for the logical principle of affirming the consequent instead of modus ponens, but is unsuccessful: we are luckily left feeling that the latter is correct instead of the former. Beebe contends that one would lack knowledge of modus ponens in such a case given that the belief, while accurate, arose in a faulty way. As Beebe notes, this scenario is similar to G. E. Moore's famous one involving the Duke of Devonshire, who dreamt he was in the House of Lords and woke up to find he was. While the belief he presumably had in the dream turned out to be true, its being based on a dream seems to preclude knowledge. Such hypothetical scenarios can then apparently be used to yield an a priori skeptical argument (Beebe 2011, p. 590):

\section{A Priori Skeptical Argument}

1. If I know that modus ponens is correct, then I know that my belief that modus ponens is correct is not based on faux intuitive experiences induced in me by a bumbling evil demon.

2. I don't know that my belief that modus ponens is correct is not based on faux intuitive experiences induced in me by a bumbling evil demon.

3. Therefore, I don't know that modus ponens is correct.

While modus ponens may be necessarily true, and our knowledge may be a priori if we have it, Beebe maintains that this does not prevent an a priori skeptic from generating the familiar skeptical hypothesis argument. In particular, unlike the previous appeals to debunking explanations or disagreement, it systematically targets the ordinary person's beliefs in putatively a priori necessities by appeal to a hypothetical scenario without assuming it's true.

Even if Beebe is right that such arguments pose challenges for putative $a$ priori knowledge, they cannot help our moral skeptic. First, like SinnottArmstrong, our skeptic is attempting to establish that we lack justification for our 
core moral beliefs. Yet Beebe's bumbling demon scenario, and the other cases like it, only pose problems for knowledge without undermining justification. As he admits "as far as a priori skepticism is concerned, you might even have a good deal of a priori justification for these beliefs" (p. 602). This is presumably because the argument exploits the widely held belief among epistemologists that factors of luck erode knowledge. In fact, Beebe's bumbling demon scenario is a kind of Gettier case: the subject seems to lack knowledge only because there is an element of luck in her justified belief turning out to be true. Yet it is precisely part of the formula for such cases that the agent is justified. So the analog in the moral case will not threaten moral justification. Our focus, however, has been on those skeptics who attack moral knowledge by attacking the justification condition on knowledge, not the conditions of truth, belief, or anti-luck. In this way, Beebe's a priori skeptic is importantly different from the traditional a posteriori one. It is certainly an interesting epistemological challenge to which one could respond elsewhere, but it is not the challenge to the justification of ordinary beliefs by appeal to the mere existence of hypothetical scenarios. It thus does not provide a model for moral skeptics to take that will undermine moral knowledge by undermining justification, in the way traditional skeptical hypotheses do by attempting to establish a version of the Equal Evidence Claim. ${ }^{13}$

Note also that Beebe's bumbling demon scenario relies on a somewhat controversial assumption about the nature of evidence in the a priori casenamely, that it consists in a kind of phenomenological seeming. This allows the bumbling demon to simply swap the feelings of veridicality around, just as the perceptual demon does. (One is reminded of the kind of indiscriminate swapping of which "qualia" are apparently capable without radical psychological effects.) There is of course a venerable sentimentalist tradition according to which moral judgments essentially involve qualitative states, such as emotions. But then a moral skeptic must defend a view of this sort to even begin constructing a demon scenario.

In the end, we have seen that one cannot simply assert that a proper skeptical scenario can be constructed that threatens our basic moral beliefs, since this seems akin to claiming that this can be done for our basic mathematical or logical beliefs. We have focused on the classical evil demon, but the problems apply to any such scenario. If the contents of one's core moral beliefs are necessarily true, then we simply cannot construct a skeptical scenario in which they seem true but aren't. Similarly, even supposing moral claims are contingent, if our beliefs in them are supported by a priori justification (if justified at all), then this status likewise seems to insulate them from attacks via skeptical hypotheses. At the very least, we have seen that skeptical hypothesis arguments against moral belief require taking on a hefty burden in treating the epistemology and metaphysics of morality as relevantly

\footnotetext{
${ }^{13}$ In addition to the bumbling demon, Beebe also mentions as a skeptical hypothesis Freud's explanation of religious belief as generated by mere wish-fulfillment, which resembles the debunking explanations we encountered in $\$ 3$. This is fitting since many conceive of such debunking explanations as involving precisely the sort of luckily or coincidentally true beliefs to which Beebe is pointing (cf. Clarke-Doane forthcoming, §3).
} 
similar to that of perception. As a result, this skeptical approach requires defending a revisionary take on these issues. Thus, even if we haven't definitively shown that a moral demon scenario cannot be constructed in the moral case, doing so clearly requires substantial argument and encounters difficulties that are not present in the perceptual case. This not only undermines the Special Force Claim; it reverses it: skeptical hypothesis arguments are less powerful against morality than perception.

\section{Conclusion}

All of the various attempts to develop a moral analog to the skeptical hypothesis argument for perceptual skepticism are problematic. Crucial features of skeptical hypothesis arguments generally fail to be met in the moral case. We have initially seen that moral nihilism is not a skeptical scenario, albeit a skeptical hypothesis. The skeptic must go further and show that an ordinary person's moral evidence fails to rule out such a skeptical hypothesis and in a way that precludes justification. Even coupled with a genealogical debunking explanation, moral nihilism does not amount to a skeptical scenario in the relevant sense, since it challenges one's beliefs by pointing to their origin rather than establishing the Equal Evidence Claim. And, while it might be true that as theorists there is substantive moral disagreement to address, this alone does not pose a special problem for morality, and it fails to properly target the justification of ordinary people's moral beliefs. Thus, focusing on moral nihilism in a skeptical hypothesis argument is fraught with difficulties.

There are further and more fundamental problems with our skeptic's argument, even if it could be properly framed in terms of moral nihilism, so that it resembles the classical deceiving demon. Any such argument incurs a host of problems when attempting to explicitly spell out a scenario in which the evidence for our moral beliefs is systematically illusory. On the face of it at least, the contents of our core moral beliefs seem metaphysically necessary or core moral knowledge seems a priori (or both). In this way, moral beliefs better resemble logical or mathematical ones, and a skeptical scenario that applies to such cases does not appear to be forthcoming. I conclude that skeptical hypothesis arguments have less force in the moral domain. Our moral beliefs are thus on safer ground. ${ }^{14}$

\section{References}

\footnotetext{
14 Many thanks to Alex Bundy, Timothy Butzer, Justin Clarke-Doane, Kevin McCain, Aaron Zimmerman, and the anonymous referees for comments on this paper, and to Walter SinnottArmstrong for helping me better understand his views. A version of the paper was presented at La Trobe University and developed while participating in the 2011 Purdue Summer Seminar on Perceptual, Moral, and Religious Skepticism, supported by the John Templeton Foundation. I thank the participants, audiences, and organizers of both events for helpful discussion, especially Michael Bergmann, Andrew Cullison, Dustin Locke, Behan McCullagh, Tim Oakley, and Ricky Sebold.
} 
Audi, Robert (1997). Moral Knowledge and Ethical Character. Oxford University Press.

Beebe, James (2011). "A Priori Skepticism.” Philosophy and Phenomenological Research 83 (3): 583-602.

Beebe, James (2010). "Constraints on Sceptical Hypotheses." Philosophical Quarterly 60 (240):449-470.

Bergmann, Michael (ms). Radical, Moral, and Religious Skepticism.

Brueckner, Anthony (1994). "The Structure of the Skeptical Argument." Philosophy and Phenomenological Research 54 (4): 827-835.

Burge, Tyler (2003). "Perceptual Entitlement." Philosophy and Phenomenological Research 67 (3): 503-548.

Clarke-Doane, Justin (forthcoming). "Moral Epistemology: The Mathematics Analogy." Noûs.

Doris, John M. (2009). "Skepticism About Persons." Philosophical Issues 19 (1):57-91.

Elga, Adam (2007). "Reflection and Disagreement." Noûs 41 (3): 478-502.

Feldman, Richard (2003). Epistemology. Upper Saddle River: Prentice Hall.

Gendler, Tamar Szabó (2000). "The Puzzle of Imaginative Resistance." Journal of Philosophy 97 (2):55-81.

Joyce, Richard (2001). The Myth of Morality. Cambridge University Press.

Joyce, Richard (2006). The Evolution of Morality. MIT Press.

McGrath, Sarah (2010). "Moral Knowledge and Experience." R. Shafer-Landau (ed.), Oxford Studies in Metaethics Vol. 6, pp. 107-127.

McNaughton, David (2008). “A Distinctively Moral Scepticism?” Philosophical Books 49 (3):207-217.

Miller, Richard (1985). "Ways of Moral Learning," The Philosophical Review 94 (4):507-556.

Nagel, Thomas (1971). "The Absurd." The Journal of Philosophy 68 (20): 716-727. Pryor, Jim (2000). "The Skeptic and the Dogmatist.” Noûs Vol. 34, No. 4, pp. 517549.

Rescorla, Michael (2009). "Epistemic and Dialectical Regress." Australasian Journal of Philosophy 87 (1): 43-60.

Shafer-Landau, Russ (2003). Moral Realism: A Defence. Oxford: Clarendon Press. Sinnott-Armstrong, Walter (2006). Moral Skepticisms. Oxford University Press.

Sinnott-Armstrong, Walter (2008a). "Summary." Philosophical Books 49 (3): 193196.

Sinnott-Armstrong, Walter (2008b). "Replies to Dreier and McNaughton." Philosophical Books 49 (3):218-228.

Wedgwood, Ralph (2010) "The Moral Evil Demons." In R. Feldman and T. Warfield (eds), Disagreement, Oxford: Clarendon Press, 216-46.

Zimmerman, Aaron (2010). Moral Epistemology. New York: Routledge. 